\title{
The choice of optimal sites for controlled landfill using the Analytical Hierarchy Process and the Geographic Information System: A case of Oum Azza in Morocco
}

\author{
Ahmed Ait Errouhi ${ }^{1}$, Jihane Gharib ${ }^{2}$, Yassir Bouroumine ${ }^{3}$ and Anas Bahi $^{3}$ \\ ${ }^{1}$ Laboratoire de 1'Ingénierie des Systèmes Avancés, Ecole Nationale des Sciences Appliquées Kénitra (ENSAK), Ibn Tofail University, \\ Morocco. \\ ${ }^{2}$ Laboratoire de Science de l'Ingénieur, Ecole Nationale des Sciences Appliquées Kénitra (ENSAK), Ibn Tofail University, Morocco. \\ ${ }^{3}$ Laboratoire de Géophysique Appliquée, Géotechnique, Géologie de l'Ingénieur et de l'Environnement, Ecole Mohammadia \\ d'Ingénieurs, Mohammed V University, Rabat, Morocco.
}

\begin{abstract}
Depending on the technical, institutional, economic and social limits of developing countries, as well as the population density in cities, nowadays, the volume of urban waste has increased considerably, and the management of this waste contributes to climate change, and air pollution, it directly affects many ecosystems and many species. Waste management faces serious problems such as irregular collection, informal sweeping activities, uncontrolled dumping and proliferation of illegal dumping. The latter constitute a real and permanent threat to the quality of life, this exponential increase in the urban population and the resulting accelerated phenomenon of urbanization have highlighted the need to develop sustainable and efficient waste management systems. Stakeholders are therefore required to consider alternative and available means of disposal, in particular by minimizing the damage caused to the ecosystem and to the human population, among these means of disposal, controlled landfills, considered as the last option in the waste hierarchy. In this study, attempts were made to locate a new landfill in Oum Azza using the AHP multi-criteria decision-making method to assess the different criteria considered during the prospecting and combining them with the geographic information system to acquire the results in the form of maps displayed on the optimal sites to house a new controlled landfill and minimize its terrible impact on the environment.
\end{abstract}

\section{Introduction}

Household waste produced in Morocco has continued to increase in recent years. The country is thus confronted with the embarrassments of waste management which is composed largely of organic matter. Subsequently, this waste was buried in illegal landfills or in old quarries located in areas close to urban centers without any treatment or control, this has posed significant risks for both public health and the environment as well as for the future of the socio-economic activities of the country [1].

All input data required for analyzes are generated from two map sources, topographic and geological maps. Topographic is used to derive six input data layers. When selecting the criteria for the siting of landfills, the data availability is taken into account. Other criteria as political and economic are excluded and will not be part of our study for lack of data. To locate potential landfills, a calculation application has been developed based on a large study and analysis of AHP method which has been widely discussed and used since its official appearance [2, 3].
Although there have been several discussions related to certain aspects of AHP theory and practice [2,4], these objections have been raised to the point that AHP constitutes one of the most common multi-criteria decision-making methods widely used around the world due to its intuitiveness and mathematical rigor [2, 3]. Perhaps the most creative task in decision making is deciding which factors to include in the reporting structure. When building hierarchies, one needs to include enough relevant detail to represent the problem as completely as possible, but not as completely as to lose sensitivity to change in items. Considering the environment surrounding the problem, identifying which attributes one feels should contribute to the solution, and who are the participants associated with the problem, are all important factors when constructing a hierarchy [5].

The organization of goals, attributes, issues, and stakeholders in a hierarchy serves two purposes: It provides an overview of the complex relationships inherent in the situation and the judgment process, and it also enables the decision maker to assess whether he is comparing problems of the same order of magnitude, subsequently the data that exist in the GIS database 
provide a simplified digital representation of land features for a given region [6]. Geo-referenced data can be organized within the GIS using different criteria, for example, as thematic layers or spatial objects. Each thematic layer can be stored using an appropriate data model depending on the data source and its potential use [2, 7 and 8$]$.

Getting the GIS and the algorithm maps that were developed will allow the evaluation of the new landfill sites based on those criteria. This helps identifying the criterion to be taken into consideration to ensure that the landfill meets legislative and environmental requirements $[1,8,9$ and 10$]$.

\section{Stakeholders in the process}

Participatory environmental modeling is a relatively new practice that involves scientists and public members working together to develop conceptual and dynamic models to solve environmental problems [1,7 and 11]. Scientists involved in the process contribute their expertise in the creation of computational models and help to keep the model scientifically sound as public stakeholders bring first-hand knowledge of environmental systems and concerns about environmental quality and human dimensions [7, 11].

In this part, we will present the different stakeholders involved in the evaluation solid waste management process. According to $[7,8]$ a stakeholder in the decisionmaking process can be defined as "an individual or a group of individuals who, by their value system, directly influences the decision, whether in the first degree due to its interventions or at the second degree by the way in which it involves those of other individuals".

As we have defined, the evaluator is the one or those who are therefore directly interested in the result of the evaluation. Sometimes the stakeholder does not have all the knowledge or skills to fully perform the assessment which implies the participation of experts, these people can often be called upon to contribute to the assessment process. These experts are then stakeholders in the evaluation process. The assessed is defined as a system. It is the subject of the evaluation, which is what the evaluation covers, in our case study is the choice of a new landfill site in Oum Azza municipality [9].

However, stakeholders bring more than their expertise to the modeling process. They participate because the approaches and results of environmental modeling influence public policies and decision-making. Stakeholders would like to have a larger role in understanding and ensuring that their voices are heard, and even more proactive functions in terms of shaping the form and processes of modeling. Modelers are also beginning to recognize the research, and policy dimensions of participatory environmental modeling, as they expand their conceptualizations of how and when to integrate "participation" into the modeling process [7 and 12].

In essence, stakeholder analysis is a project management tool, and should be repeated at intervals throughout the project cycle. The purpose of stakeholder analysis is therefore to help professionals assess the project environment and identify key people, groups or institutions with an interest in the project, and assess how their interests may affect its success.

\section{Geographic Information System GIS and AHP}

In this section we will identify the most suitable sites for landfill that require a large-scale assessment process. Any site chosen must meet government requirements and reduce environmental, economic and social costs. Restricted sites refer to areas that do not allow landfill due to potential risks (Fig. 1).

Process identification was referenced from physical, economic, social and environmental studies as well as from previous studies. The following table shows the criteria indicating unsuitable areas based on the rules under which the landfill is prohibited to be built in areas which may represent a danger to the environment (Table 1). These factors can also be used to determine which areas are suitable for waste disposal sites.

Table 1: Buffer zone criteria values

\begin{tabular}{cl}
\hline Criteria & Sites must be located more \\
\hline Dam & $>500 \mathrm{~m}$ from the dam \\
Effluents & $>300 \mathrm{~m}$ from the effluents \\
Green spaces & $>500 \mathrm{~m}$ from green spaces \\
Buildings & $>500 \mathrm{~m}$ from buildings \\
Roads & $>300 \mathrm{~m}$ from roads \\
Highway & $>500 \mathrm{~m}$ from the Highway \\
Slopes & Sites must be on areas $<5^{\circ}$ \\
\hline
\end{tabular}

In this study, based on stakeholder's opinion and literature reviews in this field, as well as the various data required and available on the study area, each criterion was classified into classes (sub-criteria), and each class has a ranking value. This was done by decision makers who gave their opinion on the sub-criteria. In order to prepare each criterion and sub-criterion, a certain number of steps were carried out in GIS (buffer, clip, superposition, conversion, reclassification and cartographic algebra) $[3,6,11$ and 12].

Among the decision support tools available in the literature, multicriteria decision support methods have seen their popularity increase considerably in recent years in environmental projects [13].

Multi-criteria decision support methods are in turn divided into different categories and include methods with a summary criterion, over-classification methods and rank methods [14 and 15]. 
Multi-criteria methods have the advantage of being able to compare different variants on the basis of a set of criteria and sub-criteria chosen jointly and help in the synthesis of information.

A calculation application was developed to identify the most [1,5 and 9] the most suitable sites in the selected potential areas. Decision making is a sequential process; it starts with defining the problem or the goal to be achieved. Once the decision problem is defined, we determine a set of criteria that reflect all the problem concerns and decide what action to take to determine at what level the degree is reached. Here, decision-makers quantified the importance of these criteria by comparing a scale from 1 to 9 (Table 2) [1, 16 and 17].

Table 2: Comparison matrix by pair of criteria

\begin{tabular}{cc}
\hline Criteria & Weight \\
\hline Dam & 2.566 \\
Effluents & 1.164 \\
Green spaces & 5.271 \\
Buildings & 16.67 \\
Roads & 17.81 \\
Highway & 26.536 \\
Slopes & 27.984 \\
\hline
\end{tabular}

The last step in the process is using the simple additive weighting method to calculate the relevance score. This method can be applied using GIS with layering capabilities. The overlay technique combines the input data layers to produce an output map (Fig. 9). Table 3 shows the relevance index calculated using the ranking values of the evaluation criteria with their corresponding relative importance weight.

Table 3: Relevance index

\begin{tabular}{cc}
\hline Relevance index & Description \\
\hline 1 & Inappropriate \\
2 & Moderately \\
3 & Adapted \\
4 & Appropriate \\
5 & More suitable \\
\hline
\end{tabular}

Table 4: Input layers used in analysis

\begin{tabular}{|c|c|c|c|}
\hline Criteria & $\begin{array}{c}\text { Sub } \\
\text { criteria }\end{array}$ & $\begin{array}{l}\text { Relevance } \\
\text { index }\end{array}$ & Weight \\
\hline \multirow{4}{*}{ Roads } & $<300 \mathrm{~m}$ & 1 & \multirow{4}{*}{2.566} \\
\hline & $300 \sim 500$ & 2 & \\
\hline & $500 \sim 1000$ & 3 & \\
\hline & $>1000$ & 4 & \\
\hline \multirow{4}{*}{ Highway } & $<500 \mathrm{~m}$ & 1 & \multirow{4}{*}{1.164} \\
\hline & $500 \sim 1000$ & 2 & \\
\hline & $1000 \sim 1500$ & 3 & \\
\hline & $>1500$ & 4 & \\
\hline \multirow{4}{*}{ Buildings } & $<500 \mathrm{~m}$ & 1 & \multirow{4}{*}{5.271} \\
\hline & $500 \sim 1000$ & 2 & \\
\hline & $1000 \sim 1500$ & 3 & \\
\hline & $>1500$ & 4 & \\
\hline \multirow{3}{*}{$\begin{array}{l}\text { Green } \\
\text { spaces }\end{array}$} & $<500 \mathrm{~m}$ & 1 & \multirow{3}{*}{16.67} \\
\hline & $1000 \sim 1500$ & 3 & \\
\hline & $>1500$ & 4 & \\
\hline \multirow{5}{*}{ Slopes } & $>20^{\circ}$ & 1 & \multirow{5}{*}{17.81} \\
\hline & $15 \sim 20$ & 2 & \\
\hline & $10 \sim 15$ & 3 & \\
\hline & $5 \sim 10$ & 4 & \\
\hline & $<5^{\circ}$ & 5 & \\
\hline \multirow{2}{*}{ Effluents } & $<300 \mathrm{~m}$ & 1 & \multirow{2}{*}{26.536} \\
\hline & $>1000$ & 4 & \\
\hline Dam & $>1500 \mathrm{~m}$ & 4 & 27.984 \\
\hline
\end{tabular}




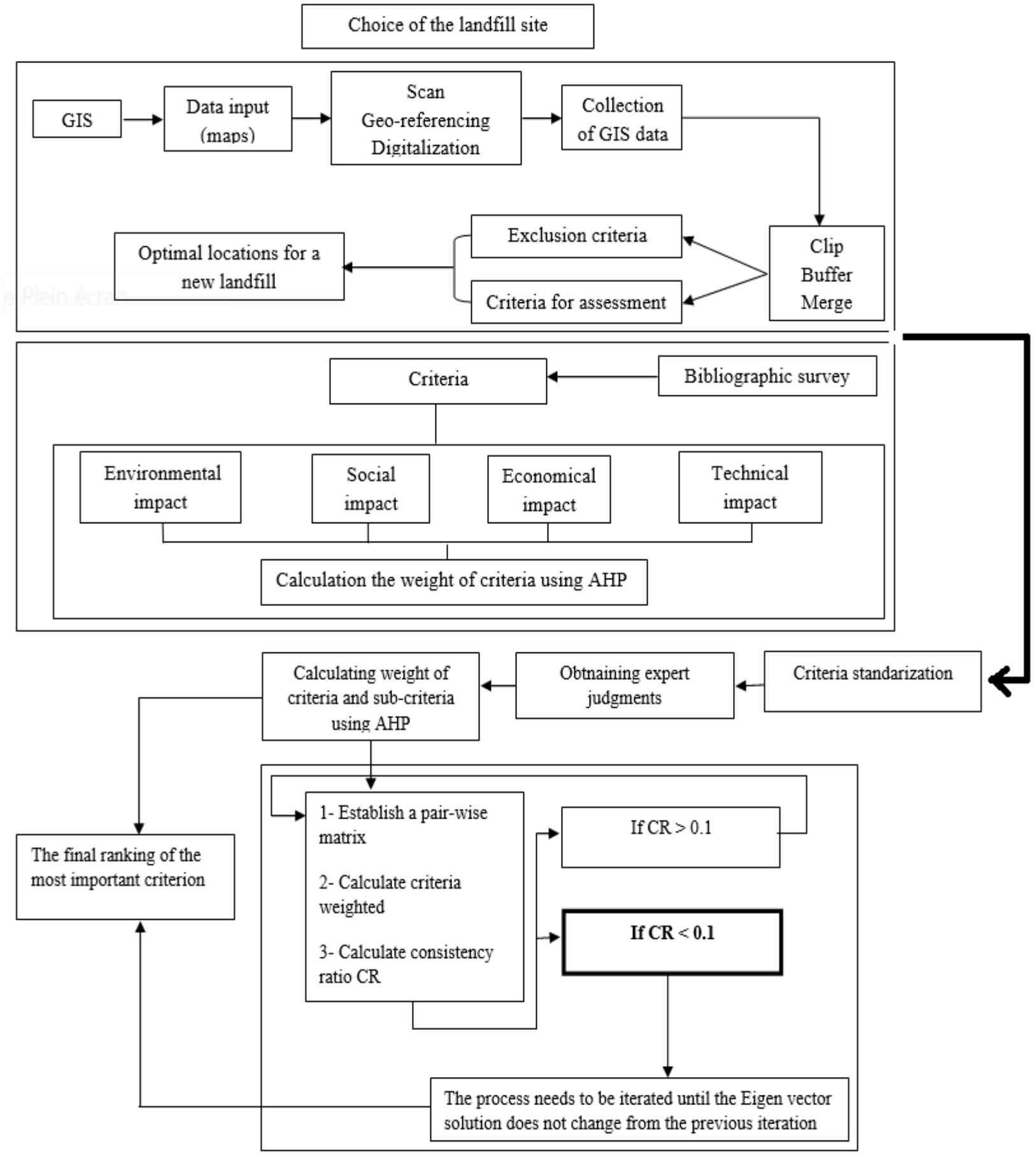

Fig. 1: The flow chart illustrating the methodology used for selection the best landfill's sites [1,9] 


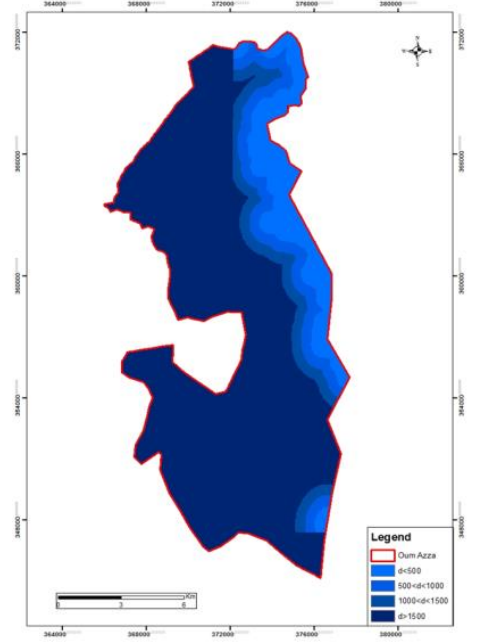

Fig . 2: Stream relevance

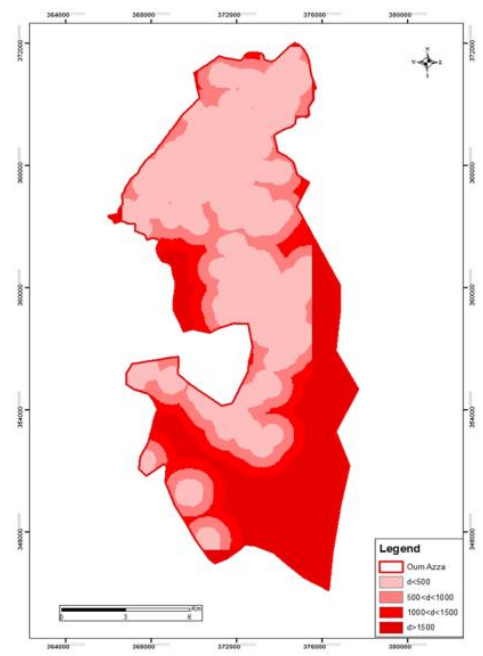

Fig. 5: Building relevance

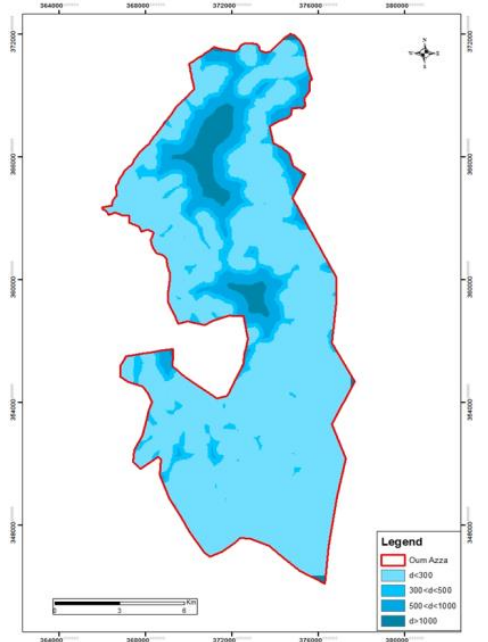

Fig. 3: Effluent relevance

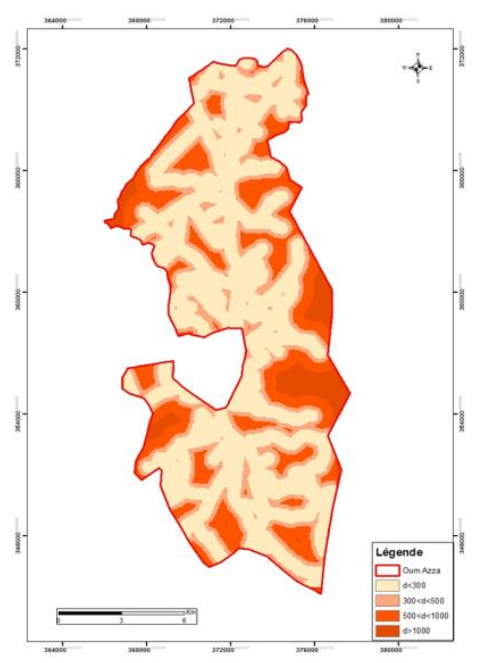

Fig. 6: Road relevance

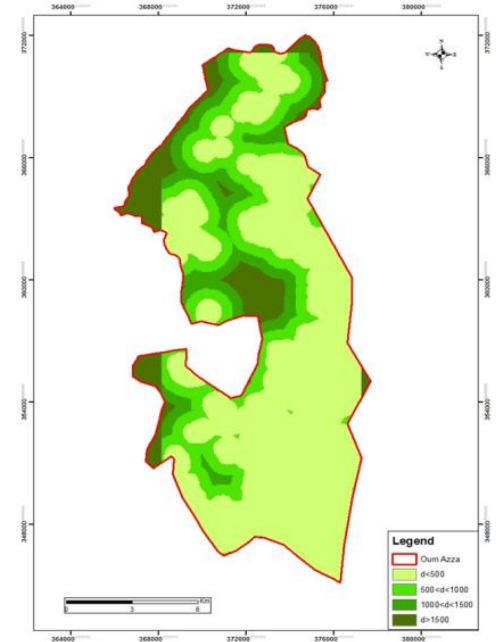

Fig. 4: Land use relevance

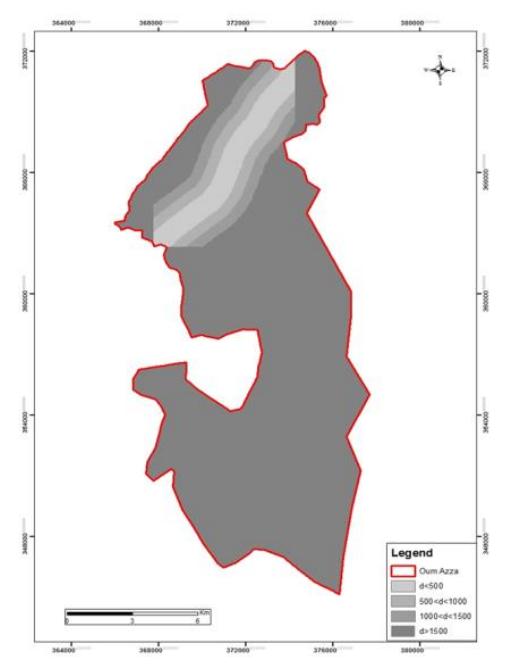

Fig. 7: Highway relevance

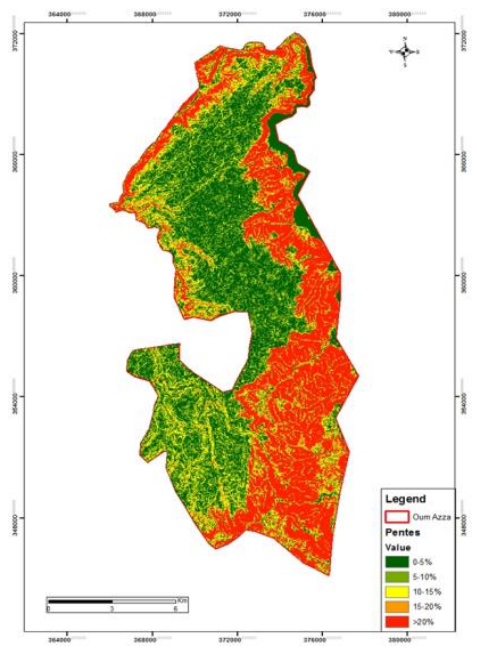

Fig. 8: Slope relevance

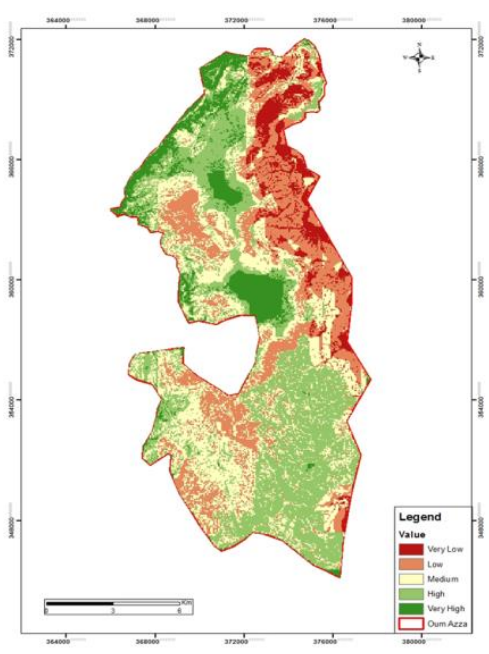

Fig. 9: Map illustrating optimal sites 


\section{Discussion \& Conclusion}

Figures 2 to 8 are the maps schematically showing the result obtained by inserting the exclusion criteria mentioned above in Table 4 into the geographic information system. Figure 9 illustrates the final result after the superposition of all the previous maps to obtain the optimal sites which will be able to shelter a controlled landfill. AHP method and the GIS system offered the means to identify candidate sites on the basis of the methodology and available data applied in this research. The results obtained showed a difference in the choice of new implantation sites, this is due to the dependence of the judgments of the stakeholders in the first stage which made it possible to extract the weights which will be introduced into the GIS to identify the homogeneous zones which can house a landfill and secondly to rank the sites obtained by GIS according to stakeholders while reducing uncertainty and defining weighting factors and ranking values. The main characteristic of our approach is the relevance of the choice of the most appropriate site for a "healthy" landfill for the benefit of Oum Azza municipality because it is the result of two techniques which take into account the imprecision of the judgments stakeholders at all stages of the process. We end this conclusion by arguing the different research visions that we plan to approach in the future to develop the approach and make improvements, implement a vigor analysis, integrate and take into account the judgment of all stakeholders ( scientists, experts, decision-makers), to develop a solid plan from the start of the solid waste chain in order to avoid any failure of the system in the long term. In addition, natural resources are becoming scarce and taking into account the temporal and spatial changes in this approach. In addition to these fumes, controlled landfills remain and are formidable agents of water pollution. In order to minimize this diffuse pollution, it is necessary to limit as much as possible the interaction of this water with the waste by suitable arrangements.

\section{References}

1. Ait Errouhi A., Bahi L., Ouadif L., Akhssas A., Bouroumine Y. and A. Bahi. Evaluation of landfill site choice using AHP and GIS case study: Oum Azza, Morocco, (2018) MATEC Web of Conferences 149, 02047.

2. Enrique $\mathrm{Mu}$, Milagros Pereyra-Rojas. "Practical Decision Making", Springer Science and Business Media LLC, (2017).

3. Roy B., Bouysson D., Aide multicritère à la décision, Economica, Paris, (1993).

4. Brunnelli, M. Introduction to the Analytic Hierarchy Process. Springer, (2015).

5. Paolisso M, Trombley J, Hood RR, Sellner KG. Environmental models and public stakeholders in the Chesapeake Bay watershed. Estuaries Coast 38:97113, (2015).

6. Chrisman Exploring geographic information systems. Jhon whiley \&Sons, NY, 2nd edition,
Geographical Information systems in the USSR, (2002).

7. Environmental Modeling with Stakeholders", Springer Science and Business Media LLC, (2017).

8. Laaribi Systèmes d'information géographique et analyse multicritère. Hermès Sciences publications, Paris, (2000).

9. Ait Errouhi A., Bahi L., Ouadif L., Akhssas A., Bouroumine Y. Landfill site selection using AHP \& TOPSIS: a case study, Oum Azza, Morocco, International Journal of Civil Engineering and Technology (IJCIET), (2018) Volume 9, Issue 7, pp. 623-632.

10. Bouroumine Y. L. Bahi, L. Ouadif Sitting MSW landfill combining GIS and analytic hierarchy process (AHP), case study: Ajdir, Morocco, International Journal of Advanced Research in Engineering and Technology, (2020), Volume 11, Issue 5, pp. 318-328.

11. Saaty, T. L. Decision Making for Leaders: The Analytic Hierarchy Process for Decisions in a Complex World. Third revised edition. Pittsburgh: RWS Publications (2012).

12. Foote et Lynch Geographic information systems as an integrating technology: Context, Concepts and definitions? Technical report, Department of Geography, University of Texas at Austin, (1996).

13. Huang, I.B., Keisler, J., and Linkov, I. Multi-criteria decision analysis in environmental sciences: Ten years of application and trends. Elsevier, Science of the Total Environment, 409 (19) : 3578-94, (2011).

14. Galvez-Cloutier, R. et Guesdon, G. 2011. Notes de cours - Impacts environnementaux (GCI-3001). Département de génie civil et de génie des eaux. Université Laval : Québec. [Consulté le 3 février 2011]; Adresse URL http://www.gci.ulaval.ca/professeurs/rgalvez/gci214 28.html, (2011).

15. André, P., Delisle, C.E. et Réveret, J.-P. L'évaluation des impacts sur l'environnement. Presses Internationales Polytechniques. 3 e edition. Canada. 398 pages, (2010).

16. Markus Neteler, Helena Mitasova. "Chapter 3 GIS Concepts and GRASS", Springer Nature, (2002)

17. Sonya Dewi, Brian Belcher, Atie Puntodewo. "Village economic opportunity, forest dependence, and rural livelihoods in East Kalimantan, Indonesia", World Development, (2005). 